\title{
Is preexisting mental illness associated with lower patient satisfaction for older trauma patients? A cross-sectional descriptive study
}

Constance McGraw ${ }^{1,2}$, Jennifer Pekarek', Diane Redmond ${ }^{2}$, Rebecca Vogel ${ }^{3}$, Allen Tanner $\|^{4}$ and David Bar-Or ${ }^{1,2^{*}}$ (I)

\begin{abstract}
Background: The purpose of this study was to examine if satisfaction with care differs among older trauma patients with and without preexisting mental illness (PMI+/PMI-).

Methods: Data from two level I trauma centers were examined from 11/2016 through 12/2017. Trauma patients $\geq 55$ years were included and satisfaction of those who had a diagnosis of mental illness prior to the trauma admission (PMI+) to those without a diagnosis (PMI) ( $n=299 ; 62$ PMI+ and $237 \mathrm{PMI}-)$ were compared. Enrolled patients completed the Family Satisfaction with Advanced Care Cancer Scale Patient Survey (FAMCARE-P13) prior to discharge. Associations between mental illness status and patient baseline characteristics, overall mean satisfaction, and mean satisfaction by question were compared. Generalized linear models adjusted for differences in patient satisfaction by mental illness status. Analyses were stratified by hospital to account for the interaction between hospital and mental illness status.

Results: Compared to PMI- patients, PMI+ patients were more likely to be younger, female, have multiple comorbidities, and to report lower overall satisfaction with care. Among PMl+ patients, the most common diagnoses were depression and anxiety. After adjustment, PMI+ was associated with lower patient satisfaction at hospital 1; after examining individual questions lower satisfaction was associated with information provided on procedures and questions surrounding "Physical care." Conversely, PMI+ did not affect satisfaction at hospital 2 after adjustment.

Conclusions: At hospital 1, room for improvement was identified in providing information about prognosis and procedures, symptom management, and continuity of care. Reexamining practices for older PMI+ trauma patients is warranted.
\end{abstract}

Keywords: Functional status, Depression, Older adults, Activities of daily living

\footnotetext{
* Correspondence: davidbme49@gmail.com

${ }^{1}$ Trauma Research Department, St. Anthony Hospital, CO, Lakewood, USA

${ }^{2}$ Trauma Research Department, Penrose-St. Francis Health Services, Colorado

Springs, CO, USA

Full list of author information is available at the end of the article
}

(c) The Author(s). 2021 Open Access This article is licensed under a Creative Commons Attribution 4.0 International License, which permits use, sharing, adaptation, distribution and reproduction in any medium or format, as long as you give appropriate credit to the original author(s) and the source, provide a link to the Creative Commons licence, and indicate if changes were made. The images or other third party material in this article are included in the article's Creative Commons licence, unless indicated otherwise in a credit line to the material. If material is not included in the article's Creative Commons licence and your intended use is not permitted by statutory regulation or exceeds the permitted use, you will need to obtain permission directly from the copyright holder. To view a copy of this licence, visit http://creativecommons.org/licenses/by/4.0/. The Creative Commons Public Domain Dedication waiver (http://creativecommons.org/publicdomain/zero/1.0/) applies to the data made available in this article, unless otherwise stated in a credit line to the data. 


\section{Background}

The growing number of injured patients admitted with preexisting mental illness (PMI) has become a concern for trauma centers across the United States in recent years [1]. According to an estimation from the National Trauma Data Bank in 2016, 10\% of patient records contained a comorbidity related to a major mental illness and estimates in the general population have reported between 18 and 26\% [2-4]. PMI can cause additional burdens for hospitalized trauma patients and has been associated with increased hospital length of stay (LOS), complications, and higher costs of care, compared to those without mental illness [5-7]. These challenges are amplified for older trauma patients, who often already face functional and cognitive decline. The Centers for Disease Control and Prevention has reported that 20\% of people aged $\geq 55$ years old suffer from mental illness, yet there is a paucity of research on PMI in older (trauma) patients [8].

Furthermore, studies show that a diagnosis of depression increases the risk of a fall or other traumatic injury particularly for older adults, as well as causing delays in functional recovery, an increased risk of a repeat fall during hospitalization, and distorted perceptions of care [9-14]. Although mental health examinations in-house are paramount for injury prevention in the elderly, studies suggest that PMI in elderly patients is frequently unaddressed by the trauma surgical staff $[9,15]$. Similar findings have been echoed in a systematic review by Mitchell and colleagues, where across 31 studies, frequent disparities existed in the physical healthcare provided to patients with mental illness compared to those without one [16]. Further complicating care of patients with PMI, older adults are also less likely than their younger counterparts to seek out help for managing their mental illness [9], potentially leading to missed opportunities for appropriate management or skewed perceptions of hospital care. Accordingly, this study explored the experience of older trauma patients with PMI while hospitalized.

The objectives of the study included: 1) measure satisfaction of older adult patients with preexisting mental illness compared to patients without mental illness; 2) characterize patients with preexisting mental illness; 3) identify areas for improvement in patient satisfaction.

\section{Methods}

\section{Study design}

This prospective cross-sectional study included trauma patients aged $\geq 55$ years, admitted between November 1 , 2016-December 31, 2017, across two level I trauma centers. Included patients were then categorized into either PMI+ (patients who had $\geq 1$ diagnosis of mental illness prior to the trauma admission) or PMI- (patients without a diagnosis) based on information contained in their medical records. Further details on the inclusion and exclusion criterion, and the processes and details for administering the surveys (including their theoretical framework and initial findings) are outlined in a previous study [17]. Briefly, eligible patients (trauma admissions $\geq 55$ years old) were approached by the study coordinators at each hospital to be enrolled. If the patient was unable to consent, they could be enrolled by proxy. Patients with severe cognitive impairment as well as those who did not meet state trauma registry inclusion criteria were excluded. Consented patients were administered the FAMCARE-P13 (Family Satisfaction with Advanced Cancer Scale, Patient), prior to discharge. The FAMCARE-P13 survey measures the degree of patient, satisfaction with information provided, availability of hospital staff, physical care management, and psychosocial care and has a possible score range of 1-65 (13 questions), with higher scores reflecting higher levels of satisfaction [18-20]. The survey questions also can be grouped into the following conceptual structures: Information giving, Availability of care, Physical care, and Psychosocial care [21].

These analyses were conducted in the context of a larger prospective study. Because this was an analysis from an ongoing study, a formal sample size calculation was not performed. Patients were provided written informed consent prior to being enrolled and surveyed. This study was carried out according to the STROBE-guidelines on the reporting of observational studies and was approved by institutional review boards at the participating centers.

\section{Standard of care}

According to the American College of Surgeons' (ACS) Guidelines for level I trauma centers, hospitals are required to screen at least $80 \%$ of all trauma admissions using screening, brief intervention, and referral to treatment (SBIRT), to identify those with problematic mental illnesses [22]. The exact process for the screening and evaluation for mental illness is left up to each trauma center. Across the hospitals in this study, a team of social workers and a clinician are usually responsible with screening patients for alcohol, substance use, and/or mental health concerns, and discerning the need for a brief or formal intervention depending on the severity of the concern.

\section{Covariates and outcomes}

The following covariates were collected on each patient from the trauma registry: sex, age $(55-65,>65)$, race, injury severity score (ISS, 1-15, $\geq 16$ ), hospital length of stay (LOS), ICU LOS, cause of injury (fall vs. high acuity vs. sport vs. other), hospital discharge destination 
(home/health vs. skilled nursing facility vs. long term care vs. hospice), the presence of the following comorbid conditions: a history of mental illness, smoking, dementia, diabetes, chronic obstructive pulmonary disease (COPD), hypertension, functionally dependent health status, anticoagulant use, congestive heart failure (CHF), alcoholism, and an advanced directive limiting care.

Covariates collected from patient EMRs included: specific mental illness diagnosis, medical insurance, mental illness management (behavioral health assessment, psychiatric consultation, discharge plans), mental illness medication, and the history of the diagnosis (longstanding mental illness: $\geq 2$ years or newer diagnosis $<2$ years), traumatic brain injury (TBI) diagnosis.

The primary outcome variable was overall mean (SD) satisfaction score for patients from the FAMCARE-P13 survey and the secondary outcome was patient satisfaction by survey question.

\section{Statistical analyses}

Satisfaction and in-hospital patient characteristics were compared univariately by the patient's PMI status. Descriptive statistics were analyzed using Chi-squared tests or Fisher's exact tests for categorical variables. Student's t-tests, one-way ANOVAs, Wilcoxon two-sample tests, or Kruskal Wallis tests were used for continuous variables, as appropriate. Data are displayed as means and standard deviations (SD), medians and interquartile ranges (IQR), or proportions.

Generalized linear models were used to determine whether differences in patient satisfaction existed between the PMI+ and PMI- patients. Entry and exit criterion were set to $p=0.2$ and $p=0.1$, respectively, and manually entered into the model. Any significant interactions between PMI status and other covariates on patient satisfaction were explored. PMI status was the primary exposure variable and thus was automatically included in each model. SAS 9.4 (Cary, NC) was used for all analyses. Two-tailed tests with an alpha $<0.05$ were used for all tests.

\section{Results}

Of the 309 patients surveyed during the study period, 10 were excluded; 9 patients upon final review did not meet state trauma registry inclusion criteria; 1 patient did not have enough information listed in the EMR to make an informed decision on mental illness diagnosis. After exclusions, there were 299 patients included in the study and of them, 62 (21\%) were PMI+ and 237 (79\%) were PMI-. Overall, the majority of patients were female (55\%), were a mean (SD) age of 73.5 (10.9) years, had a median (IQR) ISS of 9 (5$10)$, spent a median of 4 (3-6) days hospitalized, and had a mean satisfaction of $82.0 \%$ (14.2).

\section{Patient characteristics by PMI status}

Table 1 reports any differences in characteristics between patients by PMI status. Compared to patients who were PMI-, PMI+ patients had significantly lower mean (SD) satisfaction (82.9\% (13.5) vs. 78.7\% (16.2), $p=0.04)$, were more likely to be in the age range of $55-64$ vs. $\geq 65$ years $(21 \%$ vs. $35 \%, p=0.02)$, were significantly more likely to be female ( $49 \%$ vs. $74 \%, p=$ 0.003 ), to have $\geq 2$ comorbidities ( $36 \%$ vs. $92 \%, p<$ $0.001)$, and to have private insurance $(30 \%$ vs. $45 \%$, $p=0.03)$. There were no other significant differences in injury characteristics or outcomes found between groups.

\section{Characteristics of $\mathrm{PMI}+$ patients}

The most common mental illness diagnosis reported among PMI+ patients was depression (70\%), followed by anxiety (35\%), and then dementia (8\%), and in most (89\%) patients, the diagnosis was longstanding ( $\geq 2$ years) (Table 2 ). Fourteen (23\%) PMI+ patients received a behavioral health assessment (hospital 1, $n=$ 2 and hospital 2, $n=12$ ); the most common trigger for the assessment was "Coping concerns with acute change in activities of daily living" (62\%), while the remaining triggers included: "Safety concerns at home" (15\%); "Evaluation outbursts in hospital"(8\%); "Long history of depressive symptoms" (8\%), and "Suicide attempt" (8\%).

\section{Adjusted modeling for satisfaction}

Satisfaction by PMI status was modified by hospital; therefore, each adjusted model was also hospitalstratified, and data are reported in Table 3 (hospital 1) and 4 (hospital 2). After adjustment for smoking status (yes vs. no), PMI+ patients at hospital 1 had significantly lower overall satisfaction, than PMI- patients, respectively $(69.8 \%$ vs. $79.5 \%, p<0.003$, Table 3$)$. Conversely at hospital 2, after adjustment for smoking status and hospital LOS, PMI+ patients did not have significantly lower satisfaction than PMI- patients $(73.5 \%$ vs. $74.7 \%, p=$ 0.61 , Table 4). Please refer to Additional file 1 for supplementary 1 table on differences in patient characteristics by hospital.

\section{Satisfaction by survey question and hospital}

Table 5 outlines satisfaction by survey question between PMI+ and PMI- patients at hospital 1. Under Information giving, PMI+ patients had significantly lower mean satisfaction than PMI- patients with question 4, "Information provided about your prognosis (75.7\% vs. 85.6, $p=0.03$, Table 5) and question 6, "Information given about your procedures" $(73.3 \%$ vs. $88.4 \%, p=0.002)$. Interestingly, PMI+ patients also had significantly lower satisfaction than PMI- patients 
Table 1 Patient Characteristics by Preexisting Mental Illness Status

\begin{tabular}{|c|c|c|c|}
\hline Characteristics, n (\%) & $\begin{array}{l}\text { PMI+ } \\
N=62(21 \%)\end{array}$ & $\begin{array}{l}\text { PMI- } \\
N=237 \text { (79\%) }\end{array}$ & $P$-value \\
\hline Overall, mean (SD) patient satisfaction & $78.6 \%(16.3)$ & $82.9 \%(13.5)$ & 0.03 \\
\hline Sex (female) & $46(74 \%)$ & $117(15 \%)$ & 0.003 \\
\hline Age & & & 0.02 \\
\hline $55-64$ & $22(35 \%)$ & $49(21 \%)$ & \\
\hline$\geq 65$ & $41(65 \%)$ & $188(79 \%)$ & \\
\hline Injury severity score & & & 0.97 \\
\hline 1 to 15 & $56(89 \%)$ & $211(89 \%)$ & \\
\hline$\geq 16$ & $7(11 \%)$ & $26(11 \%)$ & \\
\hline Mechanism of injury (Fall) & $50(79 \%)$ & $168(71 \%)$ & 0.57 \\
\hline LOS & $5(3-7)$ & $4(3-6)$ & 0.35 \\
\hline ICU LOS & $3(2-3)$ & $2(2-3)$ & 0.30 \\
\hline ICU stay, n (\%) & $17(27 \%)$ & $89(38 \%)$ & 0.12 \\
\hline Hospital, n (\%) & & & 0.04 \\
\hline Hospital 1 & $31(50 \%)$ & $85(64 \%)$ & \\
\hline Hospital 2 & $31(50 \%)$ & $152(36 \%)$ & \\
\hline Comorbidity count & & & $<0.001$ \\
\hline$\leq 1$ & $5(8 \%)$ & $151(64 \%)$ & \\
\hline$\geq 2$ & $57(92 \%)$ & $86(36 \%)$ & \\
\hline \multicolumn{4}{|l|}{ Comorbidities (yes vs. no) } \\
\hline Smoker & $6(10 \%)$ & $20(8 \%)$ & 0.74 \\
\hline Hypertension & $33(54 \%)$ & $124(53 \%)$ & 0.82 \\
\hline Dementia & $5(8 \%)$ & $7(3 \%)$ & 0.07 \\
\hline Diabetes & $15(24 \%)$ & $35(15 \%)$ & 0.07 \\
\hline COPD & $9(15 \%)$ & $18(7 \%)$ & 0.08 \\
\hline CHF & $5(8 \%)$ & $7(3 \%)$ & 0.08 \\
\hline Type of insurance & & & 0.11 \\
\hline Medicaid & $2(3 \%)$ & $11(5 \%)$ & $>0.99$ \\
\hline Medicare & $29(47 \%)$ & $143(60 \%)$ & 0.05 \\
\hline Medicare combination & $18(29 \%)$ & $87(37 \%)$ & 0.26 \\
\hline Private & $28(45 \%)$ & $72(30 \%)$ & 0.03 \\
\hline Uninsured & $0(0 \%)$ & $6(3 \%)$ & 0.35 \\
\hline Other & $3(5 \%)$ & $5(2 \%)$ & 0.37 \\
\hline TBI diagnosis & $11(18 \%)$ & $55(23 \%)$ & 0.34 \\
\hline Discharge location & & & 0.33 \\
\hline Home/home health & $24(38 \%)$ & $111(47 \%)$ & \\
\hline LTC/SNF & $38(60 \%)$ & $125(53 \%)$ & \\
\hline Rehab & $12(19 \%)$ & $33(14 \%)$ & \\
\hline Hospice & $1(2 \%)$ & 1 (0.4\%) & \\
\hline
\end{tabular}

PMI Preexisting mental illness status (+ yes; -no), SD Standard deviation, LOS Hospital length of stay, ICU Intensive care unit, COPD Chronic obstructive pulmonary disease, CHF Congestive heart failure, TBI Traumatic brain injury, LTC Long-term care, SNF Skilled nursing facility

for all questions $(1,5,7,10,11)$ related to Physical care. Please refer to Additional file 1 (supplementary table 2) for patient satisfaction by survey question at hospital 2.

\section{Discussion}

Despite evidence showing that patients with preexisting mental illness tend to have worse outcomes and a more challenging hospitalization $[5,7]$, there is a scarcity of 
Table 2 Characteristics of Trauma Patients with $\geq 1$ Preexisting Mental Illness

\begin{tabular}{|c|c|c|}
\hline Characteristics & $N=62$ & Percent \\
\hline \multicolumn{3}{|l|}{ Number of diagnoses } \\
\hline 1 & 40 & $65 \%$ \\
\hline 2 & 20 & $32 \%$ \\
\hline 3 & 2 & $3 \%$ \\
\hline \multicolumn{3}{|l|}{ Types of Diagnoses ${ }^{a}$} \\
\hline Depression & 45 & $73 \%$ \\
\hline Anxiety & 22 & $35 \%$ \\
\hline PTSD & 2 & $3 \%$ \\
\hline Dementia & 4 & $6 \%$ \\
\hline Bipolar disorder & 2 & $3 \%$ \\
\hline Chronic pain disorder & 2 & $3 \%$ \\
\hline Fibromyalgia & 3 & $5 \%$ \\
\hline Dissociative disorder & 1 & $2 \%$ \\
\hline Personality disorder & 1 & $2 \%$ \\
\hline Drug abuse & 1 & $2 \%$ \\
\hline Mood disorder & 1 & $2 \%$ \\
\hline \multicolumn{3}{|l|}{ Management } \\
\hline Psychiatric consultation & 5 & $8 \%$ \\
\hline Behavioral health assessment & 14 & $23 \%$ \\
\hline Discharge plan & 39 & $63 \%$ \\
\hline PMI was long-standing ( $\geq 2$ years) & 55 & $89 \%$ \\
\hline PMI was being managed with medication & 48 & $77 \%$ \\
\hline
\end{tabular}

PTSD Post-traumatic stress disorder, PMI Preexisting mental illness status (+ yes; - no). aPatients can have more than one diagnosis

research on their perception of the care experience. To our knowledge, this is one of the first studies to examine satisfaction and characteristics of older trauma patients with PMI. Across two Level I trauma centers, of those who were $\mathrm{PMI}+$, the most common diagnosis was depression and patients tended to be females who were between 55 and 64 years old, and had multiple comorbidities compared to those who were PMI-. Only a small fraction of PMI+ patients qualified for a behavioral health assessment; this was particularly true at hospital 1, where only two PMI+ patients had an assessment, and reported significantly lower satisfaction with both delivery of information and physical care compared to PMI- patients.

Several of these patient characteristics have been substantiated in the published literature [5-7, 23-25].
Townsend and colleagues (2017) reported on characteristics of PMI+ trauma patients using the Nationwide Inpatient Sample (2012) and found that $44 \%$ of trauma patients $\geq 18$ years of age were PMI+ across 36.5 million patients, and similarly, PMI+ trauma patients were significantly more likely to be female, to be an average age of 61 years (vs. 56 years), and have a higher number of comorbidities compared to PMI- trauma patients [5]. In a single center study, Weinberg et al. (2016) described the prevalence and characteristics of psychiatric illness among orthopedic polytrauma patients and also discovered a significantly higher percentage of $\mathrm{PMI}+$ patients (vs. PMI-) were female (38.5\% vs. $23.7 \%)$ and had depression (22.3\%) [6].

Interestingly, smoking status was identified as an independent predictor of lower patient satisfaction at both hospitals. In this study, patients with a history of smoking had significantly more comorbidities compared to non-smokers, and significantly more also had a history of alcoholism, potentially contributing to lower satisfaction. Life satisfaction in older populations has been linked to activities that both temporarily alleviate and contribute to stress and pain, including smoking and alcohol consumption [26]. Thus, a history of smoking has been associated with lower life satisfaction [26], as well as lower patient satisfaction [17].

Nonetheless, it remains essential for trauma centers to target unmet patient needs, in order to tailor care and improve satisfaction. The identification of the most common trigger for behavioral health assessments, "Coping concerns with acute changes in ADLs", should serve as a starting point for both hospitals to best serve their older PMI+ patient population. Because this was the most common trigger, it can be surmised that these concerns are insidious among the majority of older patients, both PMI+ and PMI-. A decline in ADLs for older adults, but particularly those with dementia, has been shown to negatively affect their quality of life and perception of care [27] and furthermore, a diagnosis of depression or anxiety is associated with an increased risk of cognitive and physical decline over time for elderly patients [25, 28-33]. In this study, over half of PMI+ patients had a diagnosis of depression. Depressed patients more frequently perceive events in their life as negative compared to those without depression [34, 35] and those with depressive symptoms have previously been found

Table 3 Adjusted Model Examining Predictors of Satisfaction: Stratified by Hospital 1

\begin{tabular}{lll}
\hline Exposure variable \& covariates & $\begin{array}{l}\text { Mean Patient Satisfaction\% } \\
\text { (LSM: (95\% CI)) }\end{array}$ & $P$-value \\
\hline PMl+ vs. PMl- & $69.8(62.1-77.4)$ vs. $79.5(73.7-85.2)$ & $\mathbf{0 . 0 0 3}$ \\
History of smoking (yes vs. no) & $69.9(60.1-80.0)$ vs. 84.5 (81.3-87.7) & $\mathbf{0 . 0 0 4}$
\end{tabular}

LSM Least squares mean, Cl Confidence interval, PMI Preexisting mental illness status (+ yes; -no) 
Table 4 Adjusted Model Examining Predictors of Satisfaction: Stratified by Hospital 2

\begin{tabular}{lll}
\hline Exposure variable \& covariates & $\begin{array}{l}\text { Mean Patient Satisfaction\% } \\
\text { (LSM: (95\% Cl)) }\end{array}$ & $\boldsymbol{P}$-value \\
\hline PMI+ vs. PMI- & $73.5(68.7-78.3)$ vs. $74.7(71.4-78.0)$ & 0.61 \\
History of smoking (yes vs. no) & $68.5(62.5-74.5)$ vs. $79.7(77.2-82.2)$ & $\mathbf{0 . 0 0 5}$ \\
Hospital LOS ( $\leq 4$ days vs. $>$ 4 days) & $75.5(71.8-79.1)$ vs. $72.8(68.8-76.8)$ & 0.14 \\
\hline
\end{tabular}

LSM Least squares mean, Cl Confidence interval, PMI Preexisting mental illness status (+ yes; -no), LOS Length of stay

to be less satisfied with communication from their provider [36].

There is room for improvement across both hospitals. At hospital 2, although no difference in patient satisfaction across groups (PMI+ vs. PMI-) was identified, overall satisfaction was significantly lower than at hospital 1. This finding may be due to several reasons, one being the older patient population at hospital 2; older patients generally have less mobility, translating to lower overall life and thus patient satisfaction [26, 27, 32]. Second, patients at hospital 2 also tended to be managed on the floor, whereas at hospital 1, which included a younger population, patients had a slightly higher injury severity and typically went to critical care. At hospitals 1 and 2, satisfaction with communication of information on prognosis was significantly lower, which was identified as an area of lower patient satisfaction in a recent study on trauma patients [17], and in other patient populations [36-38]. Although these patients could in fact have been provided relevant information during their stay, significant complexities still exist in communication of information among PMI+ patients and providers $[9,14-$ $16]$, which may be more pronounced in the rush of an acute trauma setting.

At trauma centers injuries always take priority and PMI+ patients may not be flagged for a behavioral health assessment, especially if their injury is critical; however, across both trauma centers, assessments only seemed to be triggered if the PMI+ patient was clearly high-risk, potentially leaving many less obvious PMI+ patients with unmet care needs. At hospital 1 specifically, communication and management surrounding pain, prognosis, procedures, and referrals to specialists, contributed to significantly lower satisfaction, suggesting that that providers may not be closing the loop on the continuity of care after managing the injury. Closing the loop should include rigorous screening and assessment, thorough symptom management, as well as appropriate referrals for counseling and other mental health support.

Table 5 Satisfaction by Survey Question at Hospital 1

\begin{tabular}{|c|c|c|c|}
\hline Conceptual structure, Item number & $\begin{array}{l}\mathrm{PMI}+, N=31(27 \%) \\
\text { Mean\% (SD) Satisfaction }\end{array}$ & $\begin{array}{l}\text { PMI-, } N=85(73 \%) \\
\text { Mean\% (SD) Satisfaction }\end{array}$ & $P$-value \\
\hline Overall satisfaction at Hospital 1 & $78.9(19.6)$ & $88.0(13.7)$ & 0.006 \\
\hline \multicolumn{4}{|l|}{ Information giving } \\
\hline 2 Information given about how to manage pain & $82.5(23.8)$ & $87.5(17.6)$ & 0.23 \\
\hline 4 Information provided about your prognosis & $75.7(24.5)$ & $85.6(18.3)$ & 0.03 \\
\hline 6 Information given about your procedures & $73.3(32.1)$ & $88.4(18.1)$ & 0.002 \\
\hline 12 Information given about side effects & $78.3(19.4)$ & $83.3(20.0)$ & 0.24 \\
\hline 9 Answers from health professionals & $86.7(19.4)$ & $88.7(18.0)$ & 0.60 \\
\hline \multicolumn{4}{|l|}{ Availability of care } \\
\hline 3 The availability of nurses to answer your questions & $85.5(22.2)$ & $91.5(15.7)$ & 0.11 \\
\hline 8 The availability of doctors to answer your questions & $77.5(27.4)$ & $83.3(19.9)$ & 0.22 \\
\hline \multicolumn{4}{|l|}{ Physical care } \\
\hline 1 How thoroughly the doctor assessed your symptoms & $82.3(28.3)$ & $92.9(17.6)$ & 0.02 \\
\hline 5 Speed with which symptoms were treated & $75.8(25.0)$ & $88.4(15.8)$ & 0.002 \\
\hline 7 The way procedures were performed & $80.8(21.5)$ & $89.5(18.4)$ & 0.04 \\
\hline 10 Referrals to specialists & $77.0(28.8)$ & $90.1(5.5)$ & 0.009 \\
\hline 11 The way tests and treatments are followed-up by the doctor & $75.8(28.2)$ & $86.3(18.2)$ & 0.02 \\
\hline \multicolumn{4}{|l|}{ Psychosocial care } \\
\hline 13 The way the family was included in treatment and care decisions & $83.0(25.5)$ & $89.8(18.3)$ & 0.14 \\
\hline
\end{tabular}




\section{Limitations}

There are a number of limitations in the study. First, the patients responding to the satisfaction surveys may not have been representative of the general population seen across the facilities. Patients who were "very dissatisfied" or "undecided" may have withheld from taking the survey. Second, healthcare surveys administered in person can sometimes artificially inflate the results because patients might believe that their scores will negatively affect the care received; however, by capturing results soon before hospital discharge and without disclosing them to treating staff, a more accurate and unbiased description of patient satisfaction was obtained. Third, because this was a cross-sectional study of two trauma centers, other hospitals with different populations and behavioral health management strategies may not observe the same satisfaction scores; nonetheless, the inclusion of a general, older adult trauma population may help other centers hoping to understand satisfaction and characteristics of trauma patients who are PMI+. Fourth, because data was used from a larger ongoing study, the surveys used were not previously evaluated in a trauma population, or for those who are PMI+ and additional work may be needed to verify the results using an instrument tailored for this population; however, Vogel and colleagues (2019) successfully measured patient and caregiver satisfaction using the FAMCARE surveys in a trauma population $[17,39]$. Fifth, because the measurement of mental illness in this population was taken from patients who consented to take a survey, it is likely an underestimation of the true prevalence across these hospitals. Last, SBIRT components were not captured for $\mathrm{PMI}+$ patients and thus compliance with ACS guidelines was not able to be measured.

\section{Conclusions}

Older trauma patients who are PMI+ are frequently overlooked, which can lead to unmet needs and lower satisfaction with care. These findings may be indicative of hospital culture generally, in regard to older patients with preexisting mental illness. Reexamining guidelines and treatment practices for this unique patient population is warranted.

\section{Supplementary Information}

The online version contains supplementary material available at https://doi. org/10.1186/s12888-021-03071-y.

Additional file 1

\section{Abbreviations}

PMI (+/-): Preexisting mental illness diagnosis prior to trauma admission vs. without; LOS: Hospital length of stay; ACS: American College of Surgeons; SBIRT: Screening, brief intervention, and referral to treatment; ICU: Intensive care unit; COPD: Chronic obstructive pulmonary disease; CHF: Congestive heart failure; EMR: Electronic medical record; TBI: Traumatic brain injury; SD: Standard deviation; IQR: Interquartile range; ADLs: Activities of daily living; SNF: Skilled-nursing facility; LTC: Long-term care; PTSD: Post-traumatic stress disorder; LSM: Least squares mean; Cl: Confidence interval

\section{Acknowledgements}

St. Anthony Hospital and Penrose-St. Francis Hospital.

\section{Authors' contributions}

All authors provided final approval of the submitted manuscript and agree to be accountable for all aspects of the work in ensuring that questions related to the accuracy or integrity of any part of the work are appropriately investigated and resolved. CM is responsible for study conception, literature review, analysis of data, interpretation of the data, and drafting the manuscript. JP is responsible for acquisition of data, interpretation, and drafting the manuscript. DR is responsible for acquisition of data, interpretation of the data, and critical revisions. AT, RV, and DBO are responsible for interpretation of the data and critical revisions.

\section{Funding}

This research received no specific grant from any funding agency in the public, commercial or not-for-profit sectors. The study was investigatorinitiated and internal funding was provided by St. Anthony Hospital and Penrose-St. Francis Hospital.

Availability of data and materials

De-identified patient data, protocols, and statistical analysis plans are available upon reasonable request by the corresponding author: davidbme4 9@gmail.com;

ORCID ID: 0000-0002-3685-314X.

\section{Ethics approval and consent to participate}

Ethical approval in accordance with the Declaration of Helsinki was obtained from the institutional review board at all participating sites before data collection (Catholic Health IRB\#s 1023525, 975918). All participants were informed about the purpose and nature of this study and provided written informed consent to be considered for participation in the study.

\section{Consent for publication}

N/A

\section{Competing interests}

The authors declare that they have no competing interests.

\section{Author details}

'Trauma Research Department, St. Anthony Hospital, CO, Lakewood, USA

${ }^{2}$ Trauma Research Department, Penrose-St. Francis Health Services, Colorado Springs, CO, USA. ${ }^{3}$ Trauma Services Department, St. Anthony Hospital, Lakewood, CO, USA. ${ }^{4}$ Trauma Services Department, Penrose St.-Francis Health Services, Colorado Springs, CO, USA.

Received: 14 July 2020 Accepted: 25 January 2021

Published online: 30 January 2021

\section{References}

1. Fantus RJ, Dawson K. Psyched out: trauma patients with major psychiatric comorbidities. Bull Am Coll Surg. 2018;103:66-7.

2. National Trauma Data Bank 2016. Annual Report. American College of Surgeons (ACS). Available from: https://www.facs.org/-/media/files/qualityprograms/trauma/ntdb/ntdb-annual-report-2016.ashx. Accessed 13 June 2020

3. Behavioral Health Trends in the United States: Results from the 2014 National Survey on Drug Use and Health. Substance Abuse and Mental Health Services Administration (SAMSA). Available from: https://www. samhsa.gov/data/sites/default/files/NSDUH-FRR1-2014/NSDUH-FRR1-2014. pdf. Accessed 13 June 2020.

4. Kessler RC, Avenevoli S, Costello EJ, Georgiades K, Green JG, Gruber MJ, et al. Prevalence, persistence, and sociodemographic correlates of DSM-IV disorders in the National Comorbidity Survey Replication Adolescent Supplement. Arch Gen Psychiatry. 2012;69:372-80. 
5. Townsend LL, Esquivel MM, Uribe-Leitz T, Weiser TG, Maggio PM, Spain DA, et al. The prevalence of psychiatric diagnoses and associated mortality in hospitalized US trauma patients. J Surg Res. 2017;213:171-6.

6. Weinberg DS, Narayanan AS, Boden KA, Breslin MA, Vallier HA. Psychiatric illness is common among patients with orthopaedic polytrauma and is linked with poor outcomes. J Bone Jt Surg - Am Vol. 2016;98:341-8.

7. Falsgraf E, Inaba K, De Roulet A, Johnson M, Benjamin E, Lam L, et al. Outcomes after traumatic injury in patients with preexisting psychiatric illness. J Trauma Acute Care Surg. 2017;83:882-7.

8. The State of Mental Health and Aging in America. 2010, Centers of Disease Control and Prevention:1-12. Available from: https://www.cdc.gov/aging/ pdf/mental_health.pdf. Accessed on 13 June 2020.

9. Dubljanin Raspopović E, Marić N, Nedeljković U, llić N, Tomanović Vujadinović S, Bumbaširević M. Do depressive symptoms on hospital admission impact early functional outcome in elderly patients with hip fracture? Psychogeriatrics. 2014;14:118-23.

10. Lenze EJ, Munin MC, Dew MA, Rogers JC, Seligman K, Mulsant BH, et al. Adverse effects of depression and cognitive impairment on rehabilitation participation and recovery from hip fracture. Int I Geriatr Psychiatry. 2004;19: 472-8.

11. Cullum S, Metcalfe C, Todd C, Brayne C. Does depression predict adverse outcomes for older medical inpatients? A prospective cohort study of individuals screened for a trial*. Age Ageing. 2008;37:690-5.

12. Guerini F, Morghen S, Lucchi E, Bellelli G, Trabucchi M. Depressive symptoms and one year mortality among elderly patients discharged from a rehabilitation ward after orthopaedic surgery of the lower limbs. Behav Neurol. 2010;23:117-21.

13. Shamash K, O'Connell K, Lowy M, Katona CLE. Psychiatric morbidity and outcome in elderly patients undergoing emergency hip surgery: a one-year follow-up study. Int J Geriatr Psychiatry. 1992;7:505-9.

14. Callahan E, Bertakis K, Azari R, Robbins J, Helms L, Miller J. The influence of depression on physician-patient interaction in primary care. Clin Res Methods. 1996;28:346-51.

15. Dicker RA, Mah J, Lopez D, Tran C, Reidy R, Moore M, et al. Screening for mental illness in a trauma center: rooting out a risk factor for unintentional injury. J Trauma - Inj Infect Crit Care. 2011;70:1337-42.

16. Mitchell AJ, Malone D, Doebbeling CC. Quality of medical care for people with and without comorbid mental illness and substance misuse: systematic review of comparative studies. Br J Psychiatry. 2009;194:491-9.

17. Vogel R, McGraw C, Orlando A, Bourg P, Dreiman C, Peck L, et al. Examining satisfaction of older adult patients and their caregivers following traumatic injury: a cross-sectional study of three level i trauma centres. BMJ Open. 2019;9:1-9.

18. Lo C, Burman D, Rodin G, Zimmermann C. Measuring patient satisfaction in oncology palliative care: psychometric properties of the FAMCARE-patient scale. Qual Life Res. 2009;18:747-52.

19. Lo C, Burman D, Hales S, Swami N, Rodin G, Zimmermann C. The FAMCAREpatient scale: measuring satisfaction with care of outpatients with advanced cancer. Eur J Cancer. 2009:45:3182-8.

20. Parpa E, Galanopoulou N, Tsilika E, Galanos A, Mystakidou K. Psychometric properties of the patients' satisfaction instrument FAMCARE-P13 in a palliative care unit. Am J Hosp Palliat Med. 2017;34:597-602.

21. Kristjanson $\sqcup$. Validity and reliability testing of the FAMCARE scale: measuring family satisfaction with advanced cancer care. Soc Sci Med. 1993; 36:693-701.

22. Rotondo M, Cribari CSS. Resources for optimal Care of the Injured Patient-2014. Bull Am College Surgeons. 2014;79:21-7.

23. Nguyen TQ, Simpson PM, Gabbe BJ. The prevalence of pre-existing mental health, drug and alcohol conditions in major trauma patients. Aust Health Rev. 2017;41:283-90.

24. Zatzick DF, Rowhani-Rahbar A, Wang J, Russo J, Darnell D, Ingraham L, et al. The cumulative burden of mental, substance use, and general medical disorders and rehospitalization and mortality after an injury. Psychiatr Serv. 2017:68:596-602

25. Poblador-Plou B, Calderón-Larrañaga A, Marta-Moreno J, Hancco-Saavedra J, Sicras-Mainar A, Soljak M, et al. Comorbidity of dementia: a cross-sectional study of primary care older patients. BMC Psychiatry. 2014;14. https://doi. org/10.1186/1471-244X-14-84

26. Dong HJ, Larsson B, Dragioti E, Bernfort L, Levin LÅ, Gerdle B. Factors associated with life satisfaction in older adults with chronic pain (PainS65+). J Pain Res. 2020;13:475-89.
27. Giebel CM, Sutcliffe C, Challis D. Activities of daily living and quality of life across different stages of dementia: a UK study. Aging Ment Health. 2015;19. 63-71.

28. Dotson VM, Resnick SM, Zonderman AB. Differential association of concurrent, baseline, and average depressive symptoms with cognitive decline in older adults. Am J Geriatr Psychiatry. 2008;16:318-30.

29. Gonzalez-Colaço Harmand M, Meillon C, Rullier L, Avila-Funes JA, Bergua V, Dartigues JF, et al. Cognitive decline after entering a nursing home: a 22year follow-up study of institutionalized and noninstitutionalized elderly people. J Am Med Dir Assoc. 2014;15:504-8.

30. Wilson RL. Mental health and substance use. In: Mental Health; 2018. p. 137-64.

31. Reynolds CF. Meeting the mental health needs of older adults in primary care: how do we get the job done? Clin Psychol Sci Pract. 2003;10:109-11.

32. Luo MS, Chui EWT, Li LW. The longitudinal associations between physical health and mental health among older adults. Aging Ment Health. 2020;24: 1990-8.

33. Borza T, Engedal K, Bergh S, Benth JŠ, Selbæk G. The course of depression in late life as measured by the Montgomery and Asberg depression rating scale in an observational study of hospitalized patients. BMC Psychiatry. 2015;15. https://doi.org/10.1186/s12888-015-0577-8.

34. Gonda X, Pompili M, Serafini G, Carvalho AF, Rihmer Z, Dome P. The role of cognitive dysfunction in the symptoms and remission from depression. Ann General Psychiatry. 2015;14. https://doi.org/10.1186/s12991-015-0068-9.

35. Lam RW, Kennedy SH, Mclntyre RS, Khullar A. Cognitive dysfunction in major depressive disorder: effects on psychosocial functioning and implications for treatment. Can J Psychiatr. 2014;59:649-54.

36. Nelson KL, Purtle J. Perceptions of patient-provider communication and receipt of mental health treatment among older adults with depressive symptoms. Aging Ment Health. 2019;23:485-90.

37. Mann RK, Siddiqui Z, Kurbanova N, Qayyum R. Effect of HCAHPS reporting on patient satisfaction with physician communication. J Hosp Med. 2016;11: $105-10$.

38. Marcinowicz L, Chlabicz S, Grebowski R. Patient satisfaction with healthcare provided by family doctors: primary dimensions and an attempt at typology. BMC Health Serv Res. 2009;9:1-5.

39. Vogel R, McGraw C, Redmond D, Bourg (retired) P, Dreiman C, Tanner A, et al. The ACS-TQIP palliative care guidelines at two level I trauma centres: a prospective study of patient and caregiver satisfaction. BMJ Support Palliat Care. 2020. https://doi.org/10.1136/bmjspcare-2020-002229.

\section{Publisher's Note}

Springer Nature remains neutral with regard to jurisdictional claims in published maps and institutional affiliations.

Ready to submit your research? Choose BMC and benefit from:

- fast, convenient online submission

- thorough peer review by experienced researchers in your field

- rapid publication on acceptance

- support for research data, including large and complex data types

- gold Open Access which fosters wider collaboration and increased citations

- maximum visibility for your research: over $100 \mathrm{M}$ website views per year

At $\mathrm{BMC}$, research is always in progress.

Learn more biomedcentral.com/submissions 